\title{
CASAMENTO DE CRIANÇAS NO BRASIL: UM ENSAIO SOBRE COMUNICAÇÃO, POBREZA E DIREITOS HUMANOS
}

\author{
Vitória Brito Santos ${ }^{\text {iD } 1}$ e Saraí Patrícia Schmidt iD2
}

\section{Resumo}

O presente texto trata de uma reflexão acerca do tema Casamento de Crianças no Brasil, a partir de uma análise de material de cunho jornalístico. A discussão é feita tomando como base a noção de pobreza principal motivador da prática no país. Conceito este, elencado a partir da análise, que auxiliou no entendimento sobre a temática, aliada as noções de Mídia e Direitos Humanos, com o objetivo de refletir como e por que ocorre o Casamento de Crianças no Brasil, já que o país apresenta legislações que proíbem essa prática. As notícias e/ou reportagens utilizadas ajudaram a compreender que há uma emergência no debate sobre o papel da Mídia e dos Direitos Humanos frente à proteção da infância e os temas que afetam diretamente o público infantil.

Palavras-chave: Pobreza; Casamento de Crianças no Brasil; Mídia; Diretos Humanos; Notícias Midiáticas.

\section{CHILDREN MARRIAGE IN BRAZIL: AN ESSAY ABOUT COMMUNICATION, POVERTY AND HUMAN RIGHTS}

\begin{abstract}
This text deals with a reflection on the theme of Children Marriage in Brazil, based on an analysis of journalistic material. The discussion is based on the notion of poverty that motivates the practice in the country. This concept, listed from the analysis, which helped in the understanding of the theme, combined with the notions of Media and Human Rights, with the aim of reflecting how and why Child Marriage in Brazil occurs, since the country presents laws that prohibit this practice. The news and / or reports used helped to understand that there is an emergency in the debate about the role of the Media and Human Rights in the protection of children and the issues that directly affect the child audience.
\end{abstract}

Keywords: Poverty; Children Marriage in Brazil; Media; Human Rights; Media News.

\footnotetext{
${ }^{1}$ Doutoranda e Mestra em Diversidade Cultural e Inclusão Social (Universidade Feevale). Licenciada em Pedagogia (UFPEL). Bolsista Capes.

${ }^{2}$ Doutora e Metra em Educação (UFRGS) - Professora dos PPG'S em Diversidade Cultural e Inclusão Social e Processos e Manifestações Culturais da Universidade Feevale.
} 


\section{Introdução}

Ivonete não faz planos, não pronuncia desejos [...] mas responde como se sente: "Não sei direito. Sou um pouco mulher, pequena demais, meio criança também". Quando fecha os olhos, do que se lembra? "De mim desenhando pé de maçã, árvore de morango. "[...] Queria ser professora, acha que não dá mais tempo. "Espero que minha filha case bem tarde, só com 17 anos, e não engane a escola para aprender tudo bem direitinho". (ZAIDAN, 2016). ${ }^{3}$

No presente texto apresentamos uma reflexão acerca de um dos principais motivadores para a prática do Casamento de Crianças no Brasil, a pobreza. O ensaio apresenta uma relação entre educação, mídia e os direitos das crianças. Partimos de uma análise feita a partir de um recorte de notícias e/ou reportagens jornalísticas, quando identificamos a pobreza, como fator fundamental para o fato aqui analisado. Com base nessas notícias refletimos sobre a pobreza no Brasil e a forma como a mídia ocupa um papel central na construção dos discursos sociais e principalmente na formação da população, inferindo na forma como ela enfrenta esses problemas. A pobreza é um fator multidimensional que afeta grande parte da população brasileira infantil, e, causa entre tantas outras coisas o Casamento de Crianças no nosso país. Deste modo, problematizar a forma como a mídia trata o público infantil, em especial as notícias que trazem em seu discurso informações sobre a prática do Casamento ainda na infância se faz de grande importância se queremos construir uma sociedade mais justa e igualitária.

Atualmente o Brasil ocupa o 40 lugar no ranking de países com maior número de casamentos de crianças. Esses casamentos são na maioria de meninas, pois a estrutura social do Brasil, ainda se mostra patriarcal - onde o lugar da mulher é servindo ao marido -, já que as formas de dominação do sujeito infantil na nossa sociedade estão alicerçadas em muitos padrões sociais.

Fazendo uso do processo teórico-metodológico da Transmetodologia (MALDONADO, 2002) cercamos a temática investigada buscando problematizar através de um estudo analítico descritivo do fenômeno investigado, como e porque ocorre o Casamento de Crianças no Brasil. Tendo como uma das propostas ampliar o debate sobre as questões de gênero e direitos humanos, pois compreendemos as mídias como um suporte - uma educação não formal de ensino e aprendizagem - que podem auxiliar na coibição desse tipo de violência.

A questão principal que essas análises suscitam é: como o Brasil, um Estado laico, com muitas leis que trazem em seus textos capítulos de proteção à infância, está em uma posição tão elevada (40 lugar)? As análises do estudo apontaram então que a maior motivação está ligada à questão social indicando que os casamentos estão relacionados com carência financeira e maus tratos na

${ }^{3}$ ZAIDAN, Patrícia. Os bastidores da reportagem que foi buscar as crianças casadas no Brasil. Claudia, São Paulo, 8 jan. 2016. Disponível em: encurtador.com.br/wAMZ1. Acesso em: 17 out. 2017.

Perspectivas em Diálogo, Naviraí, v. 08, n. 17, p. 432-448, maio./ago. 2021. 
família. Ou seja, temos estabelecida uma relação direta dos altos índices de Casamento de Crianças no Brasil com a pobreza, conceito fundante nesta temática.

\section{Discussão: O Casamento de Crianças no Brasil}

A Organização das Nações Unidas (ONU) acredita que se nada for feito, em 2030 teremos mais de 1 bilhão de mulheres que terão se casado ainda na infância no mundo todo. A realidade do Casamento de Crianças está presente em todos os países do mundo. Atualmente estima-se que esse número seja de 700 milhões de crianças. O Fundo das Nações Unidas para a Infância (UNICEF) através de campanhas busca a erradicação do Casamento de Crianças, que infelizmente ainda está longe de acabar, "quase 14 milhões de meninas são forçadas a se casar a cada ano, ou seja, direitos humanos fundamentais são negados a 37 mil meninas diariamente. Todos os dias, nascem 7,3 milhões de bebês de mães com 17 anos de idade ou menos".

No Brasil o número de Casamentos de Crianças com menos de 18 anos é estimado em 1,3 milhão, segundo pesquisa da Universidade Federal do Pará (UFP) realizada em 2013 em parceria com o Instituto Promundo ${ }^{4}$ e a Plan International ${ }^{5}$. Sendo que 78 mil são casamentos de meninos e meninas entre 10 e 14 anos. A pesquisa realizada pelas instituições apontou que o país está em $4^{\circ}$ colocado no ranking dos países com maior número absoluto de casamentos infantis, atrás apenas de Índia, Bangladesh e Nigéria ${ }^{6}$. É uma colocação extremamente preocupante, principalmente quando no Brasil não há a questão cultural (no sentido de história de um povo) envolvida nos casamentos, ou seja, não pode ser encarado como tradição.

Quando usamos a palavra casamento não estamos nos referindo somente ao ato de unir duas pessoas perante a lei, ou perante uma religião, falamos aqui da união entre duas pessoas, sejam elas do mesmo sexo ou de sexo diferente, independente de comprovação legal, pois temos que ter isso claro quando falamos de Casamento de Crianças, já que no Brasil ele não se dá perante juízes - ou a lei do homem como é conhecida essa prática, ou perante um representante religioso -, uma vez que está previsto na nossa lei que só poderão se casar pessoas maiores de 16 anos perante autorizações judiciais.

De acordo com os dados de Mulheres, Empresas e o Direito, a idade legal para as meninas se casarem é inferior a 18 anos em 12 economias, em comparação com somente 5 no caso dos meninos. E 17 economias possuem idades de casamento diferentes para

\footnotetext{
${ }^{4}$ Organização Não Governamental (ONG) que estuda as questões de gênero desde a década de 90. A pesquisa referenciada contou com o financiamento da fundação Ford.

${ }^{5}$ Organização Mundial que trabalha pelos direitos da infância, fundada em 1937, tem sede em mais de 70 países, chegou ao Brasil em 1997 onde desenvolve projetos para combater a violência contra crianças.

${ }^{6}$ A pesquisa baseou os dados em relatório da UNICEF de 2011, que estima, em números absolutos, que 877 mil mulheres teriam se casado antes dos 15 anos. A pesquisa exclui por falta de dados países como China, Bahrein, Irã, Israel, Kuait, Líbia, Omã, Catar, Arábia Saudita, Tunísia e os Emirados Arabes Unidos, porém, todos esses possuem uma cultura ritualística do casamento enquanto tradição popular.
} 
meninos e meninas. Nesses casos, as meninas podem se casar mais cedo. (BANCO MUNDIAL, 2017, p. 2).

Sendo assim, o que faz do Brasil um país laico, com legislações firmes sobre a proteção da infância, estar em uma posição tão elevada nesse ranking? Pois bem, a maior motivação está ligada à questão social. Os casamentos ocorrem principalmente para conseguir que alguém sustente a família, ter melhores condições de vida, se livrar dos maus tratos,

Elas acham que a vida vai ser melhor morando com o marido. Mas o que elas próprias relatam é que ficaram decepcionadas. O controle que elas tinham dos pais, só passa para o marido [...]. Outra razão para manter o relacionamento é o medo de arcar sozinha com uma gravidez precoce - 39\% das meninas casadas tiveram o primeiro filho aos 15 anos - ou para fugir de abusos e maus-tratos da família?.

Assim, a maioria das crianças, principalmente meninas, se casa em busca de uma vida melhor, mas isso nem sempre acontece. Há casamentos de meninos menores de idade, no entanto, o Brasil ainda está arraigado aos pensamentos sobre o local de cada sujeito na sociedade, sendo assim, "meninas foram feitas para casar e cuidar da casa". E quando não se tem nenhuma perspectiva de melhoria da condição de vida na sua família primária, elas se voltam àquilo que aprenderam nos discursos de gênero, de que deveriam ter um marido.

Falar em gênero ao invés de falar em sexo indica que a condição das mulheres não está determinada pela biologia ou pelo sexo, mas é invenção de uma engenharia social e política. Ser homem/ser mulher é uma construção simbólica que faz parte do regime de emergência dos discursos que configuram sujeitos. (COLLING, 2004, p. 29).

Os discursos de gênero são construções sociais. As formas como as meninas sempre foram tratadas e o casamento com homens mais velhos estão arraigadas na forma como a sociedade se estruturou. De forma que a representação do "Eu" feminino e a construção identitária desses sujeitos desde a mais tenra idade está simbolicamente relacionada à diferença imposta entre os sexos, "[...] a mãe, a esposa dedicada, a 'rainha do lar', digna de ser louvada e santificada, uma mulher sublimada; [...] Aos homens o espaço público, político, onde centraliza-se o poder; à mulher o privado e seu coração, o santuário do lar" (COLLING, 2004, p. 15), esses são alguns dos discursos perpetuados até hoje e que fazem com que o Casamento de Crianças (meninas) seja maioria no país.

O Brasil além de ocupar o 40 lugar no mundo em números absolutos de mulheres casadas até a idade de 15 anos, com 877 mil mulheres com idades

\footnotetext{
${ }^{7}$ SOUTO, Isabele. Brasil é o quarto país do mundo em casamento infantil. Correio Brasiliense, Brasília, 9 set. 2015. Disponível em: https://www.em.com.br/app/noticia/nacional/2015/09/09/interna_nacional,686399/brasil-e-o-4-paisem-casamento-infantil.shtml Acesso em: 12 jun. 2016.
}

Perspectivas em Diálogo, Naviraí, v. 08, n. 17, p. 432-448, maio./ago. 2021. 
entre 20 e 24 anos que se casaram até os 15 anos (11\%), é também o quarto país em números absolutos de meninas casadas com idade inferior a 18: cerca de três milhões de mulheres com idades entre 20 e 24 anos casaram antes de 18 anos (36\% do total de mulheres casadas nessa mesma faixa etária).

Além disso, ocupamos o $4^{\circ}$ lugar também como o país com maior número de casamentos entre crianças de 10 a 14 anos - são cerca de 78 mil. Nessa faixa etária a proporção de casamentos de meninas é $48 \%$ maior que o de meninos na mesma idade, são $26 \%$ de casamentos de meninos e $74 \%$ de casamento de meninas, dados que refletem a cultura do estupro no Brasil.

Vale ressaltar aqui, que o Código Penal Brasileiro (BRASIL, 2009) traz em sua redação que qualquer ato sexual praticado com uma criança menor de 14 anos com ou sem o consentimento da vítima é estupro de vulnerável.

\section{[...] "Estupro de vulnerável"}

Art. 217A.

Ter conjunção carnal ou praticar outro ato libidinoso com menor de 14

(catorze) anos:

Pena reclusão, de 8 (oito) a 15 (quinze) anos.

§10 Incorre na mesma pena quem pratica as ações descritas no caput com alguém

que, por enfermidade ou deficiência mental, não tem o necessário discernimento para a prática do ato, ou que, por qualquer outra causa, não pode oferecer resistência [...].

[...] § 30 Se da conduta resulta lesão corporal de natureza grave: Pena reclusão, de 10 (dez) a 20 (vinte) anos.

$\S 40$ Se da conduta resulta morte: [...].

As formas como esses discursos são construídos e a incorporação dessa prática na sociedade moderna alicerçada pela pobreza do país nos faz perceber que uma infância nem tão colorida e mágica, como as mídias têm retratado ultimamente, é o que temos. Podemos pensar: por que as mídias não falam nessa cultura do Casamento de Crianças ou em tantos outros problemas "culturais" envolvendo a infância no Brasil? Aonde foi que perdemos a sensibilidade para com o problema do Outro? A exploração de vulnerável ainda é presente em todos os estados brasileiros, atingindo em maior proporção as classes menos favorecidas economicamente.

\section{Infância e Direitos Humanos}

Para a infância, os Direitos Humanos são primordiais. Quando falamos de Casamento de Crianças precisamos pensar em Direitos Humanos, afinal, a prática fere os direitos adquiridos pelas crianças ao redor do mundo. No Brasil, com a consolidação do Estatuto da Criança e do Adolescente (ECA, 1990), os direitos desse público passaram a ser garantidos pela legislação. As meninas, diferente dos séculos passados, têm o direito de estudar e dos meninos foi retirada a carga do trabalho. Sendo assim, ambos adquiriram conquistas perante 
a lei, porém, frente à forma de organização da sociedade, ainda temos sérios problemas no respeito aos direitos de cada ser infanto-juvenil, ou seja, os Direitos Humanos, no que tange a infância, ainda não conseguem cumprir o seu papel.

No Brasil e no restante do mundo, precisamos incorporar determinados discursos para que consigamos avançar nas políticas sociais que defendem a infância. Os problemas de abuso infantil - pela forma do casamento - acontecem ao redor de todo o globo, não é uma prática somente do Oriente, como muitas vezes as mídias fazem parecer. A sociedade brasileira não assume viver essa cultura patriarcal e machista, na qual o homem ainda domina a mulher. Os discursos precisam mudar junto com o período histórico, desta forma, precisa haver uma revisão das ideologias e das legislações de acordo com cada época. (SEGATO, 2006). Os grupos sociais - nesse caso as instâncias da sociedade civil que protegem as crianças - precisam tomar para si o discurso dos Direitos Humanos.

O Brasil tem uma das legislações mais avançadas do mundo no que diz respeito à proteção da infância e da adolescência. No entanto, é necessário adotar políticas públicas capazes de combater e superar as desigualdades geográficas, sociais e étnicas do País e celebrar a riqueza de sua diversidade. (UNICEF BRASIL, 2017).

O primeiro movimento concreto sobre os direitos de proteção à criança ocorre em 1924 na declaração sobre a infância feita em Genebra. Todavia, um cuidado maior com a infância ocorre somente após a Segunda Guerra Mundial, com a criação da ONU, isto é, como forma de evitar outra guerra. Inicia-se então o processo de proteção da infância. No texto base da DUDH cita-se a proteção social integral da criança, nascida dentro ou fora do casamento, e tem no seu Artigo 25 a primeira declaração de proteção à infância em nível mundial. No ano seguinte à criação da ONU, um órgão específico para a proteção da infância é criado. Nasce assim em 11 de dezembro de 1946 a UNICEF com o objetivo de proteger e promover os direitos das crianças. No Brasil a UNICEF chega somente em 1950 e tem como alvos principais de trabalho "crianças e adolescentes desfavorecidos em razão de práticas discriminatórias, questões étnicas ou raciais, situações de emergência, vulnerabilidade, deficiência, HIV/aids ou violência". (UNICEF BRASIL, 2017).

Em 1959 é aprovada a Declaração Universal dos Direitos das Crianças, composta por 10 princípios fundamentais, que versam desde o direito à igualdade, sem distinção de raça religião ou nacionalidade ao direito a crescer dentro de um espírito de solidariedade, compreensão, amizade e justiça entre os povos. (ONU, 1959). Em 1969 em San José de Costa Rica, ocorre a elaboração do documento da Conferência especializada Interamericana sobre Direitos Humanos, tendo no seu artigo 19, o texto sobre a proteção das crianças: "Toda criança tem direito às medidas de proteção que a sua condição de menor requer por parte da sua família, da sociedade e do Estado". (CIDH, 1969). O pacto firmado em San José passa a vigorar no mundo todo em 1978, até então era uma resolução só dos estados americanos. A grande mudança sobre a proteção 
da criança e a preocupação com o seu futuro ocorre de fato em 1989, é a partir da criação da Declaração dos Direitos Universais da Criança que se nota uma institucionalização da garantia dos direitos desse público.

É em 20 de novembro de 1989 que ocorre a Convenção das Nações Unidas sobre os Direitos da Criança. Na assembleia se construiu a Carta Magna para crianças de todo o mundo, o documento foi oficializado como lei internacional no ano seguinte. O Brasil promulgou a convenção em 21 de novembro de 1990, tendo sido o primeiro país da América Latina a criar uma legislação específica que atendesse às declarações firmadas na Carta Magna de 89, e também a criar o Estatuto da Criança e do Adolescente ${ }^{8}$. Criado na década de 90, durante o governo de Fernando Collor, o ECA tinha como propósito inicial a proteção da criança e do adolescente de forma integral, tendo sido regulamentado pela Lei 8.069, de 13 de julho de 1990.

O ECA traz em sua redação diversas mudanças sobre a forma de enxergar a criança. Em seu Capítulo II, artigo 18, diz que: "É dever de todos velar pela dignidade da criança e do adolescente, pondo-os a salvo de qualquer tratamento desumano, violento, aterrorizante, vexatório ou constrangedor". (BRASIL, 1990, p. 6). Assim sendo, podemos perceber que fere os preceitos legais do país o Casamento de Crianças. Acreditamos que isso se dê, pela forma como a sociedade brasileira naturalizou o Olhar sobre essa prática a ponto de muitas vezes nem saber que ela ocorre.

\section{Procedimentos Teórico-Metodológicos: As notícias Midiáticas}

A mídia pode ser compreendida como um elemento principal dentro das noções de Direitos Humanos, pois é através dela que atualmente os sujeitos tomam conhecimento das lutas sociais enfrentadas pela população ao redor de todo o mundo. O quarto poder como definido por alguns teóricos pode ser compreendida como uma instância da cidadania - neste caso a: comunicativa (MATA, 2006), sendo assim, o entendimento dos sujeitos sobre as formas pelas quais a mídia se propaga e se alicerça na sociedade são de extrema relevância se estivermos pensando em uma emancipação social desses sujeitos. (SANTOS, 2013). Pois, a mídia tem a possibilidade de contribuir positivamente no processo de tomada de direitos, e no entendimento do sujeito como agente de sua própria história.

Na sociedade temos um conjunto de direitos e deveres, e isso não é diferente com o público infantil. Todos os processos de construção de direitos que buscam a proteção integral da infância deveriam ser pautas de notícias todos os dias. Poderíamos supor que sendo o $4^{\circ}$ país no mundo em número absoluto de Casamento de Crianças, tenhamos um vasto material jornalístico sobre a temática, já que o assunto se enquadra em muitas das categorias noticiosas, tais como: proximidade, amplitude, drama, injustiça, relevância,

\footnotetext{
${ }^{8}$ O Estatuto da Criança e do Adolescente considera criança todo sujeito até 12 anos de idade e adolescente até os 18 anos. Em nossas pesquisas fazemos uso das definições da ONU/UNICEF pois consideramos que ao basear o trabalho em legislações universais o critério escolhido se torna mais abrangente.
} 
impacto - número de pessoas afetadas -, dentre tantos outros. Porém essa não é a realidade encontrada.

A aproximação exploratória revelou um silenciamento midiático sobre a temática, o que nos revela um grande problema, tendo em vista a complexidade da situação. Camacho Azurduy (2004), diz que os meios de comunicação deveriam tomar para si determinadas defesas em relação a proteção integral dos seres humanos, fazendo isso na forma de propagação das informações para um conhecimento dos sujeitos sobre determinados temas.

A partir da proposta da temática realizamos uma busca no site Google com o descritor Casamento Infantil no Brasil. Deste modo, a partir dos títulos dos links fizemos a primeira seleção: os títulos que não tinham ligação nenhuma com o tema - mesmo estando dentro do recorte de abas selecionadas conforme proposto - foram excluídos da amostra, e também os links em que o título sugeria ligação com a temática, mas ao analisar o conteúdo não havia nenhuma relação. Deste modo, restaram 74 resultados com os quais iniciamos o processo de organização dos links. Posteriormente organizamos uma tabela dividida em cinco campos: Título (correspondendo ao título do material conforme divulgado no site); Sobre o que é? (com o assunto do material); O que é (natureza do material - reportagem, notícia, artigo, vídeo, etc.); Sobre o Brasil (constava se material se referia ao país, pois apesar do descritor conter essa informação, resultados sobre o Casamento de Crianças em todo o mundo apareceram no buscador); Data (a data em que o material foi postado/produzido no site); e o Site (aqui o nome do site do qual retiramos o material) .

Após essa primeira organização, classificamos para análise somente os materiais que se referiam ao Brasil e que eram de cunho jornalístico, descartando as reportagens e/ou notícias sobre outros países (31 no total), e o sumário executivo do livro do Instituto Promundo, totalizando assim 42 reportagens e/ou notícias. Salientamos aqui que 25 das notícias e/ou reportagens falavam somente sobre os dados da Pesquisa da Instituição Promundo, ou seja, mais da metade das reportagens repetiram seu discurso (foi escolhida uma só delas). Além de que 11 reportagens e/ou notícias eram exatamente iguais e uma apresentava o link para uma reportagem que já estava no recorte da amostra (selecionamos uma de cada das que se repetiam, conforme apresentado no Quadro 1). 
Quadro 1 - Notícias e/ou Reportagens analisadas.

\begin{tabular}{|c|c|c|}
\hline TÍTULO & SOBRE E O QUE É & SITE \\
\hline $\begin{array}{l}\text { Os bastidores da } \\
\text { reportagem que foi } \\
\text { buscar as crianças } \\
\text { casadas no Brasil }\end{array}$ & $\begin{array}{l}\text { Fala sobre a motivação da jornalista em } \\
\text { fazer a reportagem Noivas Meninas - } \\
\text { Revista Claudia (janeiro de 2016) }\end{array}$ & Site $M$ de Mulher \\
\hline $\begin{array}{l}\text { Pobreza e abusos } \\
\text { estimulam casamentos } \\
\text { infantis no Brasil }\end{array}$ & $\begin{array}{l}\text { Sobre os dados da pesquisa. Ela vai no Meu } \\
\text { Barco realizada pela Promundo em parceria } \\
\text { com a UFP }\end{array}$ & Site BBC Brasil \\
\hline $\begin{array}{l}\text { Prevenção do Casamento } \\
\text { na Infância e na } \\
\text { Adolescência }\end{array}$ & $\begin{array}{l}\text { Traz informações sobre a prevenção de } \\
\text { casamentos na infância e na adolescência }\end{array}$ & Site da Promundo \\
\hline $\begin{array}{l}\text { Casamento Infantil no } \\
\text { Brasil }\end{array}$ & $\begin{array}{l}\text { Reportagem sobre as meninas que casaram } \\
\text { cedo feita pela TV Justiça de Cuiabá }\end{array}$ & $\begin{array}{l}\text { Página do } \\
\text { YouTube de } \\
\text { Sandra Rocha }\end{array}$ \\
\hline $\begin{array}{l}\text { Brasil é o quarto país } \\
\text { com mais casamentos de } \\
\text { crianças e adolescentes }\end{array}$ & $\begin{array}{l}\text { Sobre os dados da pesquisa. Ela vai no Meu } \\
\text { Barco realizada pela Promundo em parceria } \\
\text { com a UFP - cita a reportagem feita pela TV } \\
\text { Brasil }\end{array}$ & $\begin{array}{l}\text { Site EBC - } \\
\text { Replicado TV } \\
\text { BRASIL }\end{array}$ \\
\hline $\begin{array}{l}\text { Brasil é o } 40 \text { país do } \\
\text { mundo onde há mais } \\
\text { casamentos infantis }\end{array}$ & $\begin{array}{l}\text { Traz os dados da pesquisa. Ela vai no Meu } \\
\text { Barco e fala sobre as jovens no Mauí }\end{array}$ & Portal R7 \\
\hline $\begin{array}{l}\text { Gravidez precoce: Brasil } \\
\text { tem índice de país que } \\
\text { permite casamento } \\
\text { infantil }\end{array}$ & $\begin{array}{l}\text { Fala sobre os altos índices de gravidez de } \\
\text { meninas menores de } 18 \text { anos - Mesma } \\
\text { notícia do site Folha Nobre }\end{array}$ & JusBrasil \\
\hline $\begin{array}{l}\text { Brasil: Casamento } \\
\text { infantil que não se vê }\end{array}$ & $\begin{array}{l}\text { Fala sobre as práticas do casamento no } \\
\text { Brasil e naturalização disso }\end{array}$ & $\begin{array}{l}\text { Site da ANDI - } \\
\text { replicado do Diário } \\
\text { de Pernambuco }\end{array}$ \\
\hline $\begin{array}{l}\text { Casamento infantil no } \\
\text { Brasil é solução contra a } \\
\text { pobreza }\end{array}$ & $\begin{array}{l}\text { Texto de Blog sobre os dados de meninas } \\
\text { em união com homens mais velhos do } \\
\text { Censo de } 2010\end{array}$ & $\begin{array}{l}\text { Blog Nova Ótica: } \\
\text { Um novo olhar } \\
\text { para o Planeta. }\end{array}$ \\
\hline $\begin{array}{l}\text { Unicef divulga vídeo } \\
\text { chocante: parece o } \\
\text { casamento perfeito, não } \\
\text { fosse pelo final }\end{array}$ & $\begin{array}{l}\text { Vídeo institucional da UNICEF contra o } \\
\text { casamento Infantil, dados sobre o Brasil }\end{array}$ & Vix \\
\hline $\begin{array}{l}\text { Maranhão participa de } \\
\text { pesquisa sobre } \\
\text { casamento na infância e } \\
\text { na adolescência }\end{array}$ & $\begin{array}{l}\text { Sobre os dados da pesquisa. Ela vai no Meu } \\
\text { Barco realizada pela Promundo em parceria } \\
\text { com a UF, mas a reportagem tem como foco } \\
\text { a parte de entrevistas realizadas no } \\
\text { Maranhão }\end{array}$ & $\begin{array}{l}\text { Site do Governo } \\
\text { do Maranhão }\end{array}$ \\
\hline $\begin{array}{l}\text { Casamento Infantil: } \\
\text { Brasil vai mal no ranking } \\
\text { mundial }\end{array}$ & $\begin{array}{l}\text { Lembra o sequestro de meninas na Nigéria, } \\
\text { e traz dados do Casamento Infantil no } \\
\text { mundo e informações sobre a parceria } \\
\text { global "Girls Not Brides" }\end{array}$ & $\begin{array}{l}\text { UOL Blog - Dr. } \\
\text { Aleixandre Faisal }\end{array}$ \\
\hline $\begin{array}{l}\text { Brasil é o quarto país no } \\
\text { mundo em casamento } \\
\text { infantil }\end{array}$ & $\begin{array}{l}\text { Sobre os dados da pesquisa. Ela vai no Meu } \\
\text { Barco realizada pela Promundo em parceria } \\
\text { com a UFP - igual as informações do } 23,36 \text {, } \\
44,60 \text { e } 72\end{array}$ & Blog Jacó Costa \\
\hline $\begin{array}{l}\text { Brasil: casamento } \\
\text { infantil é usando por } \\
\text { meninas para evitar } \\
\text { violência doméstica }\end{array}$ & $\begin{array}{l}\text { Mostra uma imagem de uma menina } \\
\text { grávida }\end{array}$ & $\begin{array}{l}\text { Twitter do Jornal o } \\
\text { Globo }\end{array}$ \\
\hline
\end{tabular}

Fonte: Elaborado pelas autoras (2018). 
A escolha pelo material jornalístico como fonte de informação, foi feita pensando no papel social da mídia enquanto promovedor de cidadania, enquanto espaço de aprendizados e principalmente como mediadora das relações humanas contemporâneas. As mídias, com seu entrelaçamento nas dinâmicas sociais, assumem um papel primordial na construção e consolidação dos Direitos Humanos perante uma nação. Quando pensamos os problemas sociais enfrentados pelos países, conseguimos perceber a importância que as mídias têm na construção dos discursos acerca de diferentes temas e operando como um espaço de aprendizado.

Sendo assim, entendemos a mídia e sua vinculação com os Direitos Humanos como um meio de exercer cidadania comunicativa, aqui compreendida nas instâncias elencadas por Mata (2006) como os direitos civis de liberdade, de expressão e de informação que tornarão os sujeitos visíveis no espaço midiático. Compreendo, assim, que uma análise de discursos midiáticos, me ajudam a entender para além do tema estudado, me mostram como eles podem ser um estimulador desses direitos que envolvem o público infantil

\section{Análise dos Dados: A Pobreza como um Motivador do Casamento de Crianças no Brasil}

Os discursos midiáticos dessas 14 notícias e, ou reportagens nos levaram a compreender que o principal motivador do Casamento de Crianças no Brasil é a pobreza, fator que fica explícito inclusive nos títulos das notícias e reportagens, e que podemos ver nos dois trechos abaixo,

[...] no Brasil, o casamento de crianças e adolescentes é bem diferente dos arranjos ritualísticos existentes em países africanos e asiáticos, com jovens noivas prometidas pelas famílias em casamentos arranjados pelos parentes ou até mesmo forçados. $\mathbf{O}$ que acontece no Brasil, por outro lado, é um fenômeno marcado pela informalidade, pela pobreza e pela repressão da sexualidade e da vontade femininas. (ESCOSSIA, 2015, grifo nosso) ${ }^{9}$.

A criança ou adolescente engravida, algumas são obrigadas a casar; outras são seduzidas, violentadas e seguem para morar com o homem mantendo uma cultura machista de "limpar a honra da família". Há casos em que a escolaridade e a condição social e financeira da criança ou adolescente e família a empurra para essa condição. (ANDI, 2016, grifo nosso).

A pobreza é um fator multidimensional, deve ser compreendida em toda a sua amplitude, onde não só a renda per capita (pobreza relativa) é um indicativo, mas também a noção de privação de capacidades (pobreza humana).

\footnotetext{
${ }^{9}$ ESCOSSIA, Fernanda da. Pobreza e abusos estimulam casamentos infantis no Brasil. BBC Brasil, Rio de Janeiro, 9 set. 2015. Disponível em:

https://www.bbc.com/portuguese/noticias/2015/09/150908_casamento_infantil_brasil_fe_cc . Acesso em: 24 jun. 2016. 
O primeiro Relatório de Desenvolvimento Humano (RDH), feito na década de 90, colocava a renda como um meio para o desenvolvimento humano, porém com o passar dos anos, passou-se a entender a renda como indicador deste desenvolvimento e uma forma de não pobreza. Essa confusão existe até os dias de hoje, não que a renda não seja um indicativo de pobreza - e na temática aqui investigada tem forte poder de influência sobre a prática -, porém, há outros influenciadores na definição desse conceito.

A conceituação de pobreza é algo extremamente complexo. Pode ser feita levando em conta algum "juízo de valor", em termos relativos ou absolutos. Pode ser estudada apenas do ponto de vista econômico ou incorporando aspectos não-econômicos (sic) à análise, sendo contextualizada de forma dependente ou não da estrutura sócio-política da sociedade [...]. (CRESPO; GUROVITZ, 2002, p. 3).

Quando se fala em juízo de valor é pensando as visões subjetivas dos sujeitos quando definem o que são as condições básicas de satisfação ou de privação dos direitos básicos. Esse juízo de valor está diretamente relacionado às noções sociais de Qualidade de Vida (QV), ao pensar QV o fazemos principalmente nas instâncias elencadas por Minayo, Hartz e Buss (2000), nas quais os campos sociais de envolvimento de vida do sujeito são utilizados para balizar essa noção pensando duas dimensões: a subjetiva e a objetiva. Os parâmetros subjetivos, para tais autores, são: bem-estar, felicidade, amor, prazer e realização pessoal. Enquanto os objetivos são: satisfação das necessidades básicas e das necessidades criadas pelo envolvimento social e econômico da sociedade.

O primeiro documento a medir a pobreza como um fator multidimensional será o RDH de 1996, que visava a privação humana e o desenvolvimento do sujeito "medida de pobreza de capacidades" (MCKINLEY, 2008), e tinha como objetivo medir o índice multidimensional de pobreza focalizado nas capacidades, entendendo que diferente da renda per capita "as capacidades são fins e são refletidas não nos insumos, mas nos resultados em termos humanos - na qualidade de vida das pessoas". (KAKWANI, 2006, p. 9 apud MCKINLEY, 2008, p. 1). O RDH se propôs a complementar as informações do indicativo de renda utilizado para mensurar a pobreza, deste modo elencou três indicadores não monetários: educação, saúde e reprodução. Os indicadores avaliam o fim e não os meios para a pobreza já que a renda é o balizador principal para a falta das demais necessidades básicas do ser humano. O índice de pobreza humana promovido pelo RDH utilizou novos balizadores, pois compreendia que,

A abordagem da pobreza baseada em renda encontra dificuldades em medir a renda pública, como, por exemplo, as receitas públicas que financiam a provisão de serviços de saúde e educação. Além disso, a renda tem pouca correlação direta com algumas capacidades básicas, tal como a liberdade política. Dessa forma, esta abordagem não pode capturar o conjunto completo de privações humanas. (MCKINLEY, 2008, p. 1). 
Deste modo, compreende-se que precisa haver mais de um tipo de indicador para se medir a pobreza, afinal ela é multidimensional. Assim como a renda não pode ser o único balizador, a pobreza humana sozinha também não dá conta de abarcar a dimensão do conceito.

A abordagem da pobreza humana tem dificuldade em definir claramente algumas capacidades humanas. Por exemplo, será que 'o controle sobre os recursos materiais' é uma capacidade humana? Se o é, será que o nível de renda de uma pessoa (incluindo o acesso à renda pública) é uma representação adequada desta capacidade? No entanto, a renda é suposta como um meio de se desenvolver capacidades humanas, e não um fim em si mesmo. (MCKINLEY, 2008, p. 1).

Quando se pensa a pobreza como um conceito relativo, temos uma abordagem macroeconômica, pautada principalmente na noção de distribuição de renda, o que para alguns autores é o grande problema no nosso país, "o Brasil não é um país pobre, mas um país com muitos pobres". (BARROS; HENRQUES; MENDONÇA, 2000, p. 123). A pobreza relativa define como pobres as pessoas que estão situadas na camada inferior da distribuição de renda, ou seja, se comparado a outras pessoas da sociedade teriam menos de um atributo desejável (pensando as instâncias subjetivas e objetivas da QV), essa linha de pobreza relativa é que pode ser medida pela renda per capita da população.

"A desigualdade, em particular a desigualdade de renda, é tão parte da história brasileira que adquire fórum de coisa natural." (BARROS; HENRQUES; MENDONÇA, 2000, p. 123). Pensamos primeiramente no fator renda, levando em consideração o que foi afirmado pelos autores, se pensarmos que será a renda que desencadeará as demais atitudes sociais de influência na pobreza humana, inclusive se pensarmos em nível de Estado Nação. Compreendendo aqui que o aumento da renda propiciará uma emancipação social dos sujeitos o que afetaria a prática do Casamento de Crianças - já que inferiria diretamente sobre as noções subjetivas que balizam a QV dos sujeitos, portanto, auxiliam na não pobreza, quando pensada nela em sua privação de capacidades (pobreza humana). O direito a uma vida digna está previsto na lei máxima que rege o nosso país, além do direito à alimentação, saúde e moradia.

Nas notícias e reportagens selecionadas, além da questão da pobreza, vemos outros fatores influenciadores, e fica clara a questão, de que o casamento ocorre em sua maioria com as meninas.

Tanto meninos quanto meninas podem estar envolvidos em casamento infantil, no entanto, as meninas são afetadas de forma desproporcional. Experiências em vários contextos demonstram que legislação e políticas adequadas e iniciativas direcionadas a mudar normas sociais podem ter efeitos positivos na proteção do direito das meninas a decidir livremente se, quando e com quem querem casar - especialmente se estas 
proporcionarem alternativas viáveis ao casamento, como acesso à educação. (PREVENÇÃO..., 2015, grifo nosso) ${ }^{10}$.

As notícias e reportagens coletadas e analisadas mostram como os fatores sociais têm contribuído para o Casamento de Crianças, citam que a gravidez na adolescência é assim como a pobreza um dos principais motivadores, pois a ideia de controle dos corpos jovens ainda se faz presente na nossa sociedade. Deste modo, as meninas são sempre as mais afetadas pela perda de possibilidades futuras, pois são quem acabam por carregar o maior culpa quando há uma gravidez não planejada.

\section{Muitas vezes, não é apenas um desses motivos, isoladamente, e sim vários deles combinados, o que mostra a complexidade desse problema. Como consequências do casamento precoce, o Promundo identificou que, assim como na maioria dos países, as meninas tendem a engravidar cedo e a deixar a escola após o casamento para se dedicar às tarefas do lar e porque os maridos, muitas vezes, assumem o papel de ensinar as jovens. Assim, as menores já iniciam um casamento no qual não há igualdade entre marido e mulher. (SANTOS, 2016, grifo nosso) ${ }^{11}$.}

As próprias notícias e reportagens mostram a falta de informação e conhecimento sobre o assunto. Há um sério problema de discurso midiático sobre as temáticas que envolvem a infância. Os dados apresentados pelo Instituto Brasileiro de Geografia e Estatística (IBGE) de casamentos de meninas com idade até 19 anos mostra como a falta de políticas públicas contribui com a prática, pois ao invés de o número diminuir conforme o passar dos anos, há oscilações que são agravadas pelos períodos econômicos no país.

Se você pensa que casamento infantil é absurdo praticado somente na Índia, faz parte da maioria de cidadãos que - como eu e gestores de muitas instituições públicas - precisa nacionalizar o olhar e mirar para o próprio umbigo. Esta é uma tragédia invisível no Brasil. Pior: "Ninguém está pensando nesta questão", alerta Alessandra Nilo, coordenadora da Gestos, ONG do Recife voltada para defesa de Direitos Humanos, comunicação e gênero. (BRASIL..., 2016, grifo nosso) ${ }^{12}$.

Charaudeau (2008), ao falar do enunciador e do enunciado, nos lembra que a linguagem é um processo cultural, ele faz parte de um contexto que atravessa a forma como os discursos são construídos, assim sendo, as notícias analisadas se destinam a receptores diversos, entretanto o local de fala dos

${ }^{10}$ PREVENÇÃo do casamento na infância e na adolescência. Promundo, [S.I.], 2015. Disponível em: https://promundo.org.br/programas/pesquisasobrecasamentoinfantil/ . Acesso em: 12 jun. 2016.

${ }^{11}$ SANTOS, Marta. Brasil é o $4^{\circ}$ país do mundo onde há mais casamentos infantis. Portal R7, São Paulo, 8 mar. 2016. Disponível em: https://entretenimento.r7.com/mulher/brasil-e-o-4-pais-do-mundo-onde-ha-mais-casamentosinfantis-08032016. Acesso em: 12 jun. 2016.

12 BRASIL: Casamento infantil que não se vê. Andi Comunicação e Direitos, [S.I.], 16 jun. 2016. Disponível em: http://www.andi.org.br/clipping/brasilcasamentoinfantilquenaoseve .Acesso em: 12 jun. 2016. 
veículos de comunicação está situado no campo da informação, ou seja, há um contrato com o receptor que compreende os meios de comunicação como um local onde podem procurar informações acerca de fatos do cotidiano, e que estas informações serão verdadeiras e irão falar sobre a realidade em que aquele sujeito está inserido.

Sendo assim, o número irrisório de reportagens encontradas sobre a temática é uma expressão da forma como os enunciadores entendem o contexto onde vivem. Eles não o compreendem na verdade, e por isso a importância de ver como os estudantes de Comunicação têm aprendido sobre esse assunto, se esse Não-Olhar o Outro é uma questão de formação profissional, pois se há um contexto, por que não há um discurso?

O resultado de notícias encontradas sobre o Casamento de Crianças no Brasil também mostra como o Oriente ainda é visto como o povo "bárbaro" que obriga suas meninas a casarem, porém, o retrato brasileiro não é diferente. Mesmo assim ele não é noticiado da forma como deveria ser, bem como a instância da pobreza infantil no Brasil não tem merecido a atenção que deveria da mídia. Muitos são os motivos pelos quais isso ocorre, cremos que o maior deles seja a naturalização do olhar. Uma naturalização que leva ao entendimento de que os Direitos Humanos são um processo universal de "salvamento" dos povos do Oriente, e não uma prática que precisa ser intercultural e contra hegemônica. (SANTOS, 2008).

\section{Considerações finais}

A desigualdade é uma das marcas mais expressivas da sociedade brasileira, é um fenômeno transversal, multidimensional e durável (SCALON, 2011), aliada aos marcadores sociais (pobreza e gênero), fazem das meninas pobres um, "sujeito nenhum". A leitura das notícias mostrou ao mesmo tempo que o silenciamento da mídia é reflexo do silenciamento da sociedade. 0 pequeno número de reportagens encontradas sobre a temática é uma expressão da forma como os enunciadores entendem o contexto onde vivem. 0 silenciamento midiático acerca desse tema, nos levou a refletir que estamos negligenciando esses sujeitos - em um processo de não pertencimento enquanto ser social de direitos. Muitos outros fatores sociais confluem com a temática aqui apresentada, porém a mídia pode ser um local de aprendizado, se o Olhar com o qual se trata as minorias e se produz material para elas for feito de forma correta

A forma de ser e estar no mundo precisa ser revista, precisamos começar a encarar os problemas relativos à infância como problemas sociais, que precisam do auxílio de todos para serem resolvidos, a forma como a mídia trata a infância e se dirige a essa infância faz parte desses problemas. Ademais, as políticas sociais precisam ser políticas de Estado e não de Governo. Bauman (2009) reflete acerca da necessidade de vermos a política social como uma política de base para o funcionamento do Estado-Nação, no caso da temática aqui investigada, políticas que não só sejam asseguradas por lei (porque pelo que analisamos elas estão na legislação), mas políticas que levem ao bem estar 
social, coisa que não temos no Brasil, que é quando compreendemos o Outro como parte da estrutura da sociedade.

\section{REFERÊNCIAS}

AGÊNCIA DE NOTÍCIAS DOS DIREITOS DA INFÂNCIA (ANDI COMUNICAÇÂO E DIREITOS). Infância e Juventude, Brasil: Casamento infantil que não se vê, Brasília, 2016

BANCO MUNDIAL. Fechando a Brecha: Melhorando as Leis de Proteção à Mulher contra a Violência. Washington, 2017.

BARROS, Ricardo Paes; HENRIQUES, Ricardo; MENDONÇA, Rosane.

Desigualdade e pobreza o Brasil: retrato de uma estabilidade inaceitável.

Revista Brasileira de Ciências Sociais, v. 15, n. 42, p. 123-142, fev., 2000.

BAUMAN, Zygmunt. Confiança e Medo na Cidade. Rio de Janeiro: Jorge Zahar Ed, 2009.

BRASIL. Constituição (1988). Constituição da República Federativa do Brasil de 1988. Disponível em:

http://www.planalto.gov.br/ccivil_03/constituicao/constituicao.htm. Acesso em 12 jun. 2019.

BRASIL. Lei no 8.069 de 13 de julho de 1990. Dispõe sobre o Estatuto da Criança e do Adolescente, e dá outras providências. 3. ed. Porto Alegre: Assembleia Legislativa, 2008.

BRASIL. Lei no 12.015, de 7 de agosto de 2009. Altera o Título VI da Parte Especial do Decreto-Lei no 2.848, de 7 de dezembro de 1940 - Código Penal, e o art. 10 da Lei no 8.072, de 25 de julho de 1990, que dispõe sobre os crimes hediondos, nos termos do inciso XLIII do art. $5^{\circ}$ da Constituição Federal e revoga a Lei no 2.252 , de $1^{0}$ de julho de 1954, que trata de corrupção de menores. Disponível em: http://www.planalto.gov.br/ccivil_03/_ato20072010/2009/lei/l12015.htm. Acesso em: 24 jun. 2019.

CAMACHO AZURDUY, Carlos A. Democratización de la sociedad: Entre el derecho a la información y el ejercicio de la ciudadanía comunicativa, Sala de Prensa, [S.I.], Ano 6, v. 3, n.71, p. 1.10, 2004.

CHARAUDEAU, Patrick. Problemas de abordagem na análise do discurso. In: CHARAUDEAU, Patrick. Linguagem e discurso: modos de organização. São Paulo: Contexto, 2008. 
COLLING, Ana. A construção histórica do masculino e do feminino. In: STREY, Marlene N.; CABEDA, Sonia T. Lisboa; PREHN, Denise R. (Orgs.). Gênero e Cultura: questões contemporâneas. Porto Alegre: EDIPUCRS, 2004. p. 13-38.

COMISSÃO INTERAMERICANA DE DIREITOS HUMANOS (CIDH). (1969).

Convenção americana sobre os direitos humanos: assinada na Conferência especializada interamericana sobre direitos humanos, San José, Costa Rica, 22 nov. 1969. Disponível em:

https://www.cidh.oas.org/basicos/portugues/c.convencao_americana.htm. Acesso em: 18 ago. 2019.

COMPARATO, Bruno Konder. Especialização em Educação em Direitos Humanos. São Paulo: USP, 2015.

CRESPO, Antônio Pedro Albernaz; GUROVITZ, Elaine. A pobreza como um fenômeno multidimensional. RAE- eletrônica, São Paulo, v. 1, n. 1, p. 1-12, jul./dez, 2002.

MALDONADO, Alberto Efendy. Produtos midiáticos, estratégias, recepção. A perspectiva transmetodológica. Ciberlegenda, n. 9, p. 1-15, 2002.

MARTINS, José de Souza. A sociedade vista do abismo: novos estudos sobre exclusão, pobreza e classes sociais. 3. ed. Rio de Janeiro: Vozes, 2008.

MATA, Maria Cristina. Comunicación y ciudadanía: problemas teóricos: políticos de su articulación. Fronteiras - Estudos Midiáticos, São Leopoldo, v.8, n.1, p. 5-15, jan. /abr. 2006.

MCKINLEY, Terry. O que é pobreza? Boa pergunta. Centro Internacional de Pobreza, Brasília, n. 26, p. 1-2, fev./2008.

MINAYO, Maria Cecília; HARTZ, Zulmira Maria de Araújo; BUSS, Paula Marchiori. Qualidade de vida e saúde: um debate necessário. Ciência e Saúde Coletiva, Rio de Janeiro, v. 5, n. 1, p. 7-18, 2000.

NOBLAT, Ricardo. A arte de fazer um jornal diário. 7. ed. São Paulo: Contexto, 2008.

O COMEÇO DA VIDA. Direção: Estela Renner, Produção: Maria Farinha Filmes, Brasil: UNICEF, Instituto Alana, Fundação Maria Cecília Souto Vidigal, Fundação Bernard Van Leer, 2016. 1 DVD (1h37min), son., color.

ORGANIZAÇÃO DAS NAÇÕES UNIDAS - ONU. Declaração Universal dos Direitos das Crianças. [S.I.], 20 nov. 1959. Disponível em: http://www.dhnet.org.br/direitos/sip/onu/c_a/lex41.htm . Acesso em: 12 jun. 2019. 
SANTOS, Boaventura de Souza. A gramática do tempo: para uma nova cultura política. 2. ed. São Paulo: Cortez, 2008.

SANTOS, Boaventura de Souza. Poderá o direito se emancipatório. Revista Crítica de Ciências Sociais, n. 65, p. 3-75, maio, 2013.

SCALON, Celi. Desigualdade, pobreza e políticas públicas: notas para um debate. Contemporânea, São Paulo, v. 1, n. 1, p. 49-68, jan./jun. 2011.

UNICEF. Escritório Brasil. Biblioteca. UNICEF no Brasil. Brasília, DF, 2017. Disponível em: http://www.unicef.org.br/ . Acesso em: 12 jun. 2019.

Recebido em: 08 de dezembro de 2020. Aceito em: 26 de março de 2021. Publicado em: 30 de junho de 2021. 